\title{
Conducting a serials review project
}

\author{
By Lee E. Pike
}

\author{
Head of the Business Library \\ The University of Alabama
}

With serials prices spiralling out of control and new journal titles appearing at a brisk rate, it is no surprise that many libraries' serials budgets are unable to keep up with increasing costs. Moreover, in this age of limited funding, some libraries' serials budgets are shrinking instead of growing. In this environment, the serials collection must be examined with a critical eye. Cancellation of unused or little-used titles becomes an economic necessity, but weeding must be done very carefully in order to minimize its impact on patrons. Each new title must also be carefully weighed to determine whether it merits a place in the collection.

The Business Library at the University of Alabama undertook a major serials review beginning in early 1988. At first glance, the serials budget was not in critical condition; it was growing sufficiently to maintain the current collection and add a new title occasionally. However, about one-third of the faculty members served by the Business Library had joined the university within the previous six years. Since very few new titles had been added during that time, the collection did not accurately reflect the requests of the library's primary patron group. Furthermore, the Business Library had been paying for a substantial number of important serials with private foundation funds. This funding ceased in 1988, forcing the Business Library to pick up these serials with its regular budget. This new expense could be met only if cuts were made. As a reward for completing a serials review in good faith, the Business Library was promised a modest increase in its serials budget.

\section{The library}

The Business Library is a departmental library within the University of Alabama Libraries system. It serves the College of Commerce and Business Administration and is physically located in the business school building. The college comprises approximately 4,400 undergraduates, 400 graduate students, and 120 faculty members in a variety of disciplines: economics, finance, labor, accounting, statistics, marketing, international business, etc. The Business Library receives very heavy use from each of these patron groups, as well as from students and faculty outside the college and from the local business community. There are two professional librarians, and the collection numbers approximately 150,000 volumes. Because of the heavy demands on the library and the faculty's demonstrated interest, the librarians considered it very appropriate to involve the college faculty in the review process as much as possible.

\section{Phase I}

The initial step in the review process was a faculty evaluation of the Business Library's periodical subscriptions. A massive listing of 1,150 periodical titles ( 24 pages on legal-size paper) was sent to each faculty member. One of five evaluations could be selected: "essential," "important," "useful," "possible candidate for deletion," or "unfamiliar with this title." Surprisingly, over half of the faculty members took the time to go through the list and evaluate titles. This response rate was a clear indication of the faculty's interest in the project. The results of this initial questionnaire were tabulated to show the number of responses in each category.

At this point, there was a delay in the project. Turnover occurred in the Business Library's professional positions, and by the fall of 1988 there were two new librarians. Both librarians were interested in continuing the serials review project because of the opportunity it provided to assess the collection. The project was broadened to cover not only periodicals but also certain reference serials.

\section{Phase II}

The next step in the project was to send the faculty three lists, each with the following fivepoint rating scale: "seldom or never useful," "sometimes useful," "useful," "important," "essential." The first list contained the titles of 219 periodicals which no faculty member had designated as either essential or important, in response to the initial questionnaire. The price was shown for each title. The list was headed, "Currently Received Journals: Candidates for Cancellation." The cover memo explained that it was necessary to identify titles to delete in order to reallocate funds to new titles. The second list was a compilation of all the unfilled 
requests for new titles which had been submitted to the library during the preceding few years. Prices were also shown. The librarians hoped to use this list to discover which of the requested titles generated the most interest. Finally, the third list contained the titles and prices of the serials, primarily reference serials, which had previously been purchased with the private foundation funds. The purpose of this list was twofold: to determine the relative need for those particular titles and to educate the faculty about the high costs of reference serials and the severe impact that the loss of the private funds was having on the Business Library's serials budget. Although the faculty was given only two weeks to return the lists, the response rate was again quite good.

Tabulation of the responses was conducted in a different manner for each list. The purpose of the first list was to identify candidates for deletion. The librarians decided to divide the list into sections which reflected both the level and the number of responses. By building each section onto the previous sections, they could establish a possible deletion list with the titles in priority order. For example, Section A contained all titles which received either no votes or only the lowest possible rating. There were 35 titles in this section, and their prices were added. Section B contained titles which had received fewer than four level-3 votes, and no higher level votes. This section also contained titles which had received only level-2 votes; 51 titles fell into this category. Their prices were added to the total amount in Section A. Section C contained only five titles: those which had received more than four level-3 votes, but no higher votes. Section D contained titles with three or fewer level-4 votes and those with only one level- 5 vote ( 58 titles), and Section $\mathbf{E}$ contained the remainder ( 70 titles). The prices for the titles in each section were totalled and added to the total prices of the previous sections. These subtotals would provide the librarians with guidance on how many titles would have to be deleted in order to generate the necessary funds.

Tabulation of the second list proceeded in a similar manner. This list contained titles of new periodicals requested by faculty members over the previous few years. The tabulation for this list gave somewhat more emphasis to the number of votes a given title received. Section A contained 36 titles which had received seven or more votes, including at least one level- 5 vote, the highest possible rating. The prices of the titles were totalled. Section B contained titles with six or fewer votes but at least one level- 5 vote. The prices of the 16 titles in the section were totalled, then added to the Section $A$ total. Section $\mathrm{C}$ contained the remainder of the titles from the list. None of these 12 titles had received a level-5 vote. Their prices were also totalled, and that amount was added to the previous subtotal. Naturally, this list generated a flurry of still more new journal requests. In some cases, faculty members collected signatures from a few colleagues to demonstrate the level of demand for the title. These new requests were added to the tabulation in a separate category.

Tabulation of the responses for the third list was much less structured. This list contained the serials formerly purchased with private foundation funds. Most of them were reference serials which the librarians considered essential for the collection. The faculty agreed: 18 of the 23 titles received at least one level-5 vote. Only one title received no votes above level 3 . That title and two others which had received four or fewer votes, none of them at level 5 , were identified as candidates for cancellation. The prices of the other titles were added to determine how much savings would be required to add them to the serials budget.

All of the tabulations having been concluded, there remained a great deal of work to do on the project. The price of each title was doublechecked; because the project was conducted over an extended period of time, many prices had gone up. In order to be able to update prices and totals more easily, the lists were loaded into a series of spreadsheets on the library's microcomputer. Some of the low-rated periodicals were found to be gifts, in which case theywere removed from the list. In other cases, subscriptions were part of a package, requiring consideration of how the package might be affected if one of the titles were cut.

\section{Phase III}

The librarians took the process well beyond an evaluation of current periodicals. The reference shelflist was examined in order to identify which reference serials were on standing order and which were purchased regularly or irregularly with monograph funds. From these groups of titles, three new lists were generated: a standing order cancellation list, a standing order request list, and a list of standing orders which could be converted to alternate-year purchases. Prices were researched and spreadsheets drawn up.

Eventually, the librarians had put together a series of seven spreadsheets, three of which represented needs and four of which represented possible resources. The lists of needs were: new periodical requests, serials formerly purchased with private foundation funds, and standing orders for reference serials normally purchased out of monograph funds. The lists which identified possible sources of funds for reallocation were: periodical cancellations, standing order cancellations, standing order savings through alternate-year purchases, and a fourth list describing savings which had already been accomplished by other means- 
e.g., cancellation of a duplicate title or the termination of a title. Totals from each spreadsheet were used to create a master summary of the funds involved in the project.

At this point, the librarians were faced with some difficult decisions. Their goal was to maximize the number of new titles added while minimizing the number and impact of the cancellations. The list of possible periodical cancellations was studied closely. Where the only two titles in a particular area were both candidates for deletion, the decision was sometimes made to keep one title. Very inexpensive titles which had been specially requested by a faculty member were removed from the cancellation list. The librarians also considered what reference value each title had, where it was indexed, how frequently it was requested through interlibrary loan, and how often the students used it. A list of candidates evolved which contained 46 titles from the two lowest sections in the tabulation.

The list of requests for new periodicals was also examined. After verifying prices, etc., the librarians arrived at a list of $\mathbf{5 6}$ titles. Every title which had received a level-5 vote was on the request list, as well as several of the recent requests generated by the project. The titles on the standing order cancellations list and the alternate-year purchases list were weighed carefully against the list of foundation-funded serials and the new standing order requests. Tradeoffs were made based on the librarians' perceptions of information needs. Twenty of the 23 foundation-funded serials were added to the budget, and 42 new standing orders were placed. The standing order cancellations, alternate-year purchasing, etc., affected just 26 titles.

Once the final lists were drawn up and compared, it was discovered that only $\$ 2,300$ in new

\section{"Living Treasures"}

Six employees of the Library of Congress have been named "living treasures" by the Global Library Project, a series of cable television programs produced in conjunction with Jones International Ltd.'s Mind Extension University. The series named: Samuel Brylawski, a reference librarian in the sound reference center of the Motion Picture, Broadcasting, and Recorded Sound Division; Barbara Morland, head of telephone reference in the General Reading Rooms Division; Ford Peatross, curator of the archaeology, design, and engineering collections in the Prints and Photographs Division; Stephanie Selby, reading room assistant in the microforms section of General Reading Rooms; Hazel Williams, a specialist in the Serial Record Division; and Thompson Yee, a cataloger in Collections Services. monies would be needed to implement the plan. As a final precaution, the librarians sent a list of the proposed periodical cancellations and additions to the faculty. Only one title on the list of periodicals for cancellation was identified as a title which should be kept, and this title was kept. Finally, the various lists were submitted to the technical services department for implementation.

\section{Conclusion}

The serials review project was an extremely valuable experience for the librarians in the Business Library. It enabled them to familiarize themselves quickly with a substantial portion of the collection and assess it. It also proved to be an excellent public relations vehicle for involving the faculty in library activities. There are, of course, other methods of conducting such projects; the present librarians were somewhat constrained in their choice of methods by the procedures used in the initial phases by the previous librarians. For example, having the entire faculty review the entire periodicals collection may not be strictly necessary. Also, it may well be profitable to assess at least part of the collection each year, rather than doing a major project every five to ten years. On the whole, it seems clear that the necessary evil of weeding the serials collection, when carefully managed, may have the side benefits of fine-tuning the collection and enhancing public relations for the library.

\section{Faculty Status: 2001}

The Academic Status Committee of ACRL is organizing a day long Think Tank on faculty status immediately proceeding the 1992 Midwinter Meeting in San Antonio, Texas. The Think Tank is intended to explore issues related to faculty status that must be dealt with in the coming decade. It is hoped that the Think Tank will set an agenda for promoting and keeping alive the value of faculty status for academic librarians in the future.

The Think Tank team will be made up of approximately six librarians and six provosts representing a variety of academic institutions. Nominations (self-nominations are welcome) for members of this team are now invited. Nominations should be accompanied by a curriculum vitae and a letter detailing the nominee's qualifications for participating in a Think Tank on faculty status. The deadline for receipt of nominations is May 21, 1991. Please send all nominations to: Gemma DeVinney, BI Coordinator, Lockwood Memorial Library, SUNY at Buffalo, Buffalo, New York 14260; (716) 6362817; FAX (716) 636-3859. 